\title{
THIRD COMPONENTS WITH ELLIPTICAL ORBITS IN THE ECLIPSING BINARIES
}

\author{
D. E. Tvardovskyi ${ }^{1,2}$ (D), V. I. Marsakova ${ }^{2}$ (D), I. L. Andronov ${ }^{1}$ (iD \\ ${ }^{1}$ Department of Mathematics, Physics and Astronomy, \\ Odesa National Maritime University, Odesa, Ukraine \\ ${ }^{2}$ Department of Theoretical Physics and Astronomy, \\ Odesa I. I. Mechnikov National University, Odesa, Ukraine
}

(Received 30 September 2019; in final form 20 June 2020; accepted 23 June 2020; published online 07 October 2020)

\begin{abstract}
In our research, we studied 9 eclipsing binary stars: AR Lac, U CrB, S Equ, SU Boo, VV UMa, WW Gem, YY Eri, V0404 Lyr, HP Aur. We collected large sets of moments of minima from BRNO and observational data from AAVSO databases. Then, we obtained the moments of minima for AAVSO observations (totally 397 minima) using the method of approximation with symmetric polynomial, realized in software MAVKA. This software was provided by Kateryna D. Andrych and Ivan L. Andronov. Then, we combined the obtained moments of minima with the data taken from BRNO and plotted $\mathrm{O}-\mathrm{C}$ diagrams. For all the stars, these diagrams represented sinus-like oscillations with the superposition of a linear trend (for SU Boo, VV UMa, WW Gem, V0404 Lyr and HP Aur) or a parabolic trend (for AR Lac, U CrB, S Equ and YY Eri). The oscillations could be described as the presence of the third component, which does not take part in eclipses, but causes the well-known light-time effect (LTE). That effect could be easily detected using long data series of observations. However, the oscillations show clear asymmetry, which we interpreted by an elliptical shape of the third components' orbit. The parabolic trend is explained by a mass transfer between components of a binary system. For all the stars, we computed the minimal possible mass of the third component. In addition, we developed our own code in the computed language Python and, using it, we computed orbital elements of the third component. For the stars with a parabolic trend, we calculated the mass transfer rate. For all computed values, the errors (accuracy) were estimated.

Key words: stellar astrophysics, eclipsing binary, mass transfer, third component, orbital elements, O-C diagram.
\end{abstract}

DOI: https://doi.org/10.30970/jps.24.3904

\section{INTRODUCTION}

\section{A. General information}

For this research, we have chosen 9 eclipsing binaries: AR Lac, U CrB, S Equ, SU Boo, VV UMa, WW Gem, YY Eri, V0404 Lyr, HP Aur. All of them are well-known stellar systems and were observed during a long period of time (80-150 years). To carry out our research, we took some general parameters (period, initial epoch, variability type etc.) of the systems from the "General Catalogue of Variable Stars" (GCVS [1]). The masses of the binary systems were taken from previously published articles. All these parameters are collected in Table 1.

Unfortunately, only for three stellar systems (AR Lac, WW Gem and HP Aur), the errors of the component masses were provided. For all other stars, we supposed that the errors of masses for the primary and secondary components are equal to $7 \%$ of their masses. This value is equal to the average relative error of the stellar masses determination. In addition, there is a lot of information published before in other articles by different authors.

\begin{tabular}{|c|c|c|c|c|c|}
\hline Stellar system & Initial epoch (JD-2400000) & Period (days) & $M_{1}, M_{\odot}$ & $M_{2}, M_{\odot}$ & Ref \\
\hline AR Lac & 41593.7123 & 1.98319204 & $1.26 \pm 0.02$ & $1.12 \pm 0.02$ & {$[2]$} \\
\hline U CrB & 16747.9718 & 3.45220133 & 4.8 & 1.4 & {$[3]$} \\
\hline S Equ & 42596.74348 & 3.4360969 & 3.24 & 0.42 & {$[4]$} \\
\hline SU Boo & 52500.895 & 1.561258 & 2.5 & 0.3 & {$[5]$} \\
\hline VV UMa & 45815.3365 & 0.68738 & 1.93 & 0.44 & {$[6]$} \\
\hline WW Gem & 25984.257 & 1.237811 & $4.39 \pm 0.33$ & $2.11 \pm 0.16$ & {$[6]$} \\
\hline YY Eri & 41581.624 & 0.32149415 & 1.54 & 0.62 & {$[7]$} \\
\hline V0404 Lyr & 35836.462 & 0.73094585 & 1.35 & 0.51 & {$[8]$} \\
\hline HP Aur & 46353.236 & 1.4228191 & $0.9543 \pm 0.0041$ & $0.8094 \pm 0.0036$ & {$[9]$} \\
\hline
\end{tabular}

Table 1. General information about investigated stars 
B. AR Lac

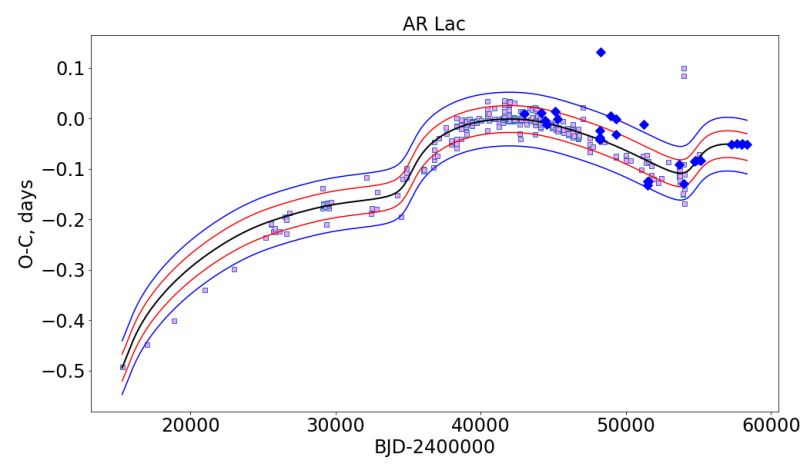

Fig. 1. O-C curve of AR Lac. For each star we plotted O$\mathrm{C}$ curve and made approximation. Small squares are the observations from database BRNO, large rhombs are the ones that we determined from AAVSO observations. The lines show the approximation and the $\pm 1 \sigma$ and $\pm 2 \sigma$ "error corridors", where $\sigma$ is a biased estimate of the r.m.s. deviation of a single point from the approximation.

There are more than 200 articles published before, thus we analyze only the most important of them. The third component was supposed in [10-12]. In all the three articles, the mass of the third component was estimated. However, the orbital parameters were not computed. The mass transfer was assumed in [11], [13-15] and [10]. In the last four of these articles, the rate of the mass transfer was computed.

\section{U CrB}

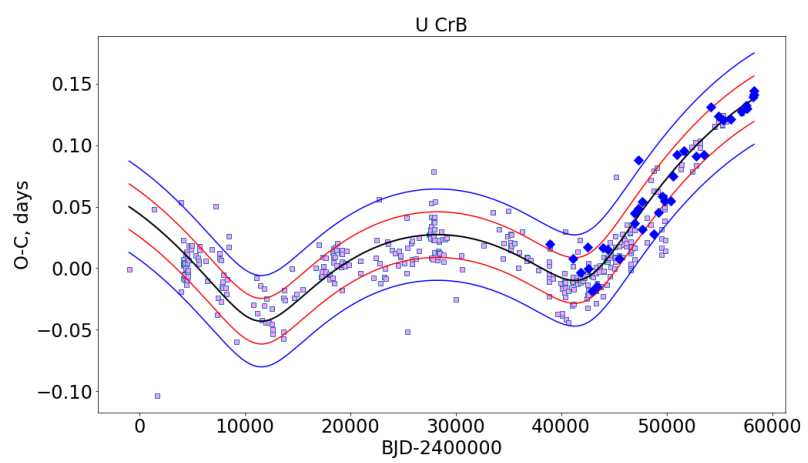

Fig. 2. $\mathrm{O}-\mathrm{C}$ curve of $\mathrm{U} \mathrm{CrB}$

The mass transfer was supposed in [16-25]. The rate of the mass transfer was computed in [16], [18], [21], [26] and [24]. The third component as the reason for cyclic period changes was supposed in [16], [26-30]. The third component's mass was computed in [16], [29-31]. Orbital elements were estimated in [27] and [29]. Moreover, in [26] the fourth component was supposed and its mass was computed.
D. S Equ

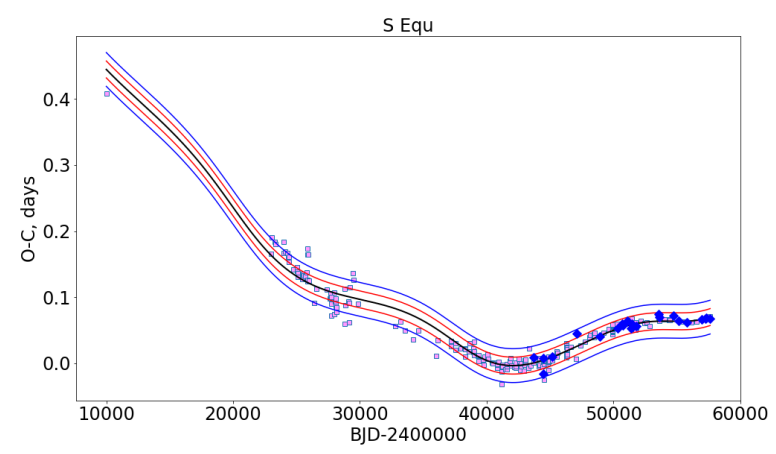

Fig. 3. O-C curve of S Equ

The mass transfer was supposed and its rate was determined in [31-36]. The third component was assumed and its mass was computed in [34-35]. Moreover, in [34] parameters of the third component's orbit were calculated.

\section{E. SU Boo}

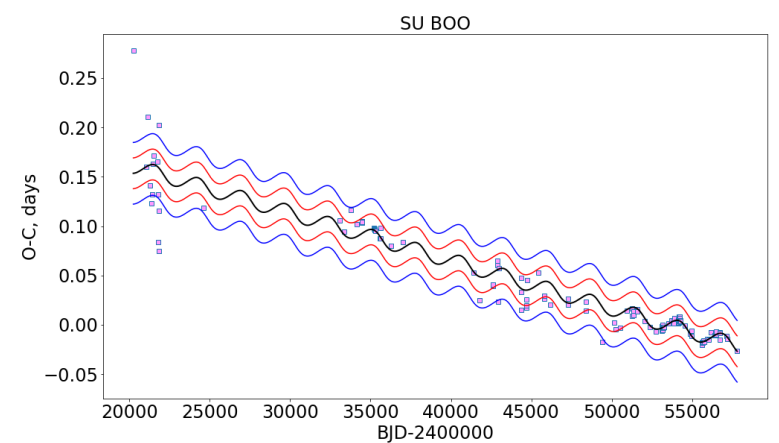

Fig. 4. O-C curve of SU Boo

In [37], a complex analysis of the third component and the mass transfer hypothesis were made. The rate of the mass transfer was computed, as well as the third component's mass and the parameters of its orbit.

\section{F. VV UMa}

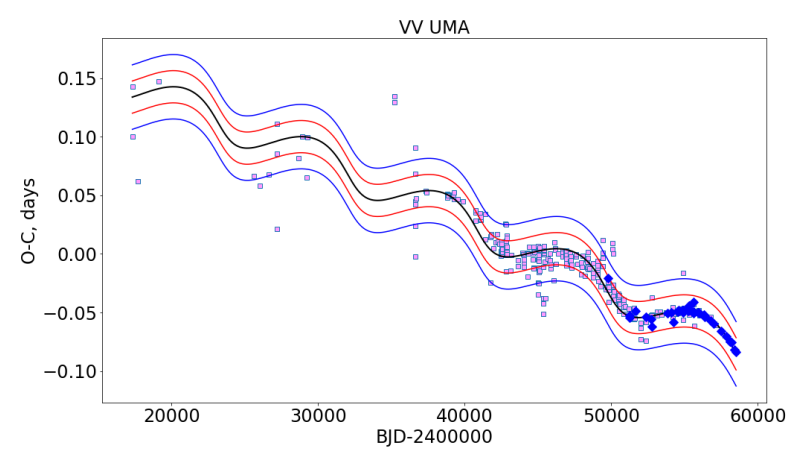

Fig. 5. O-C curve of VV UMa 
In [37], the hypothesis of the presence of the third component was proposed; the parameters of the orbit and the mass were calculated.

\section{G. WW Gem}

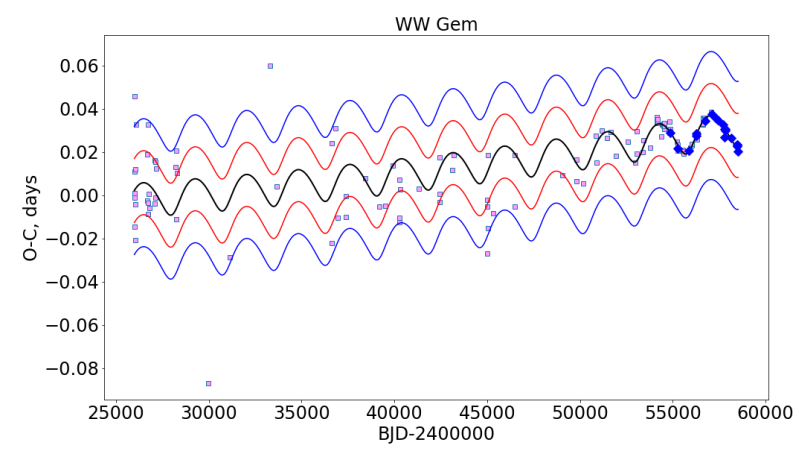

Fig. 6. O-C curve of WW Gem

The analysis of the third component and the mass transfer was made in [38]. The mass, orbital elements and the mass transfer rate were determined.

\section{H. YY Eri}

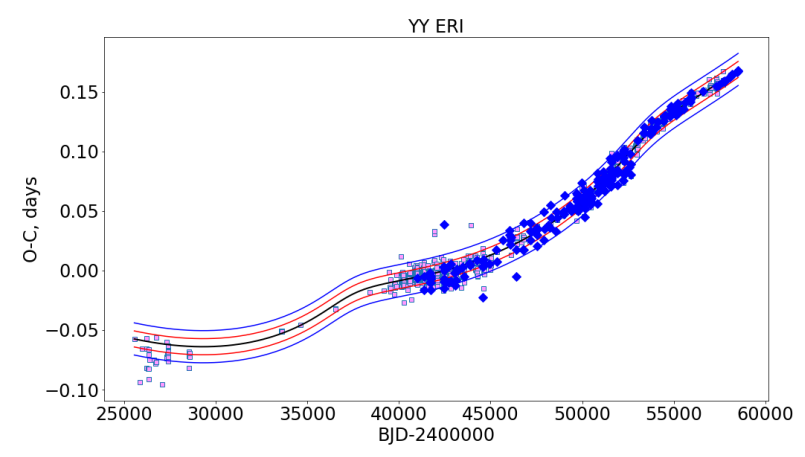

Fig. 7. O-C curve of YY Eri

In [39], the third component was supposed and its mass was computed.

\section{V0404 Lyr}

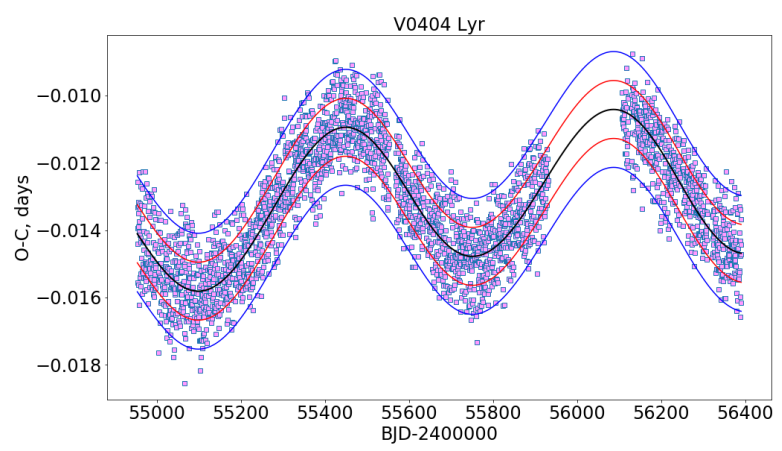

Fig. 8. O-C curve of V0404 Lyr
In [40], both the third and the fourth components were supposed and their masses obtained. The mass transfer rate was computed as well.

\section{J. HP Aur}

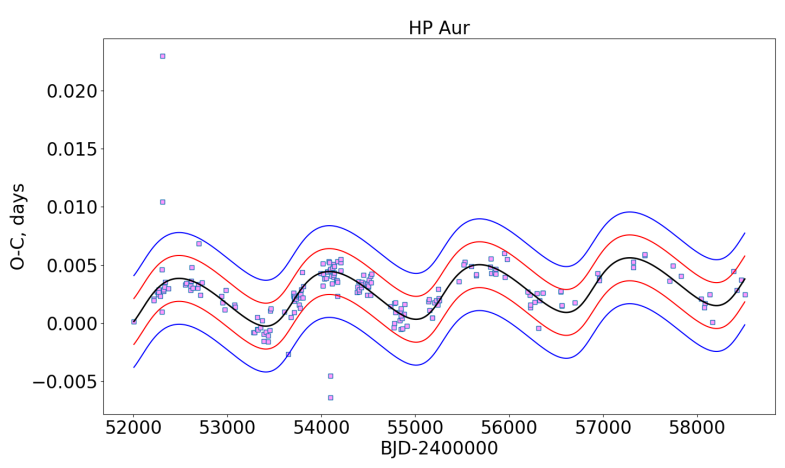

Fig. 9. O-C curve of HP Aur

No analysis of either the mass transfer, or of the presence of the third component was made in any article.

\section{METHODS AND ALGORITHMS}

One of the methods of detection of the third components in eclipsing binary systems, is the $\mathrm{O}-\mathrm{C}$ analysis. The $\mathrm{O}-\mathrm{C}$ curve is the dependence on time of the deviations of the observed moment of minimum from the calculated one. This method is one of the simplest, when the third component is neither visible, nor taking part in the eclipses. It is appropriate for any possible mass of the third component, if this mass is enough to make $\mathrm{O}-\mathrm{C}$ oscillations larger then the noise. In this case, we can suggest the presence of the third component without spectroscopic observations, and even can estimate some of its orbital parameters. On the other hand, the third components usually have a long orbital period. That is why several decades of regular observations are needed. This is called LTE (the Light-Time Effect).

If the $\mathrm{O}-\mathrm{C}$ curve has sinus-like oscillations, we can sugest the presence of the third component, which makes the binary system to rotate around common barycenter in a circular orbit. This motion causes a delay (either positive or negative) of the minimal brightness moment. If we plot the dependence of the delay on time we get a sinusoid-like O-C curve. After calculating the amplitude and the period of such changes, we can estimate the minimal possible mass of the third component. Though sometimes the oscillations have clear asymmetry but stay periodic, which might be caused by the elliptical shape of the third component's orbit. Parameters of such an orbit could be estimated by special algorithms.

In the case of a parabolic shape of $\mathrm{O}-\mathrm{C}$ or a parabolic trend with the superposition of cyclic period changes, we suppose the presence of a mass transfer between 
components of a binary system. If $\mathrm{O}-\mathrm{C}$ is linear, it could be caused by an error in the initial period determination.

We estimated the minimal possible mass of the third component using the third Kepler's law and the formula of the barycenter position. Then we supposed that the orbit of the third component is perpendicular to the picture plane (thus we get the minimal possible value). After simplifications, we got the formula for the minimal possible mass of the third component:

$$
M_{3}=\frac{c \cdot \Delta t}{\sqrt[3]{G}} \cdot\left[\frac{2 \pi}{T} \cdot\left(M_{1}+M_{2}+M_{3}\right)\right]^{\frac{2}{3}} .
$$

The real mass of the third component is not less than this minimal value. The maximal value is formally not limited. The minimal value depends on the semi-majour axis of the third component's orbit, that could be slightly different for various models.

To compute the masses of the third components, it is necessary to use this formula with several iterations. The error of the minimal possible mass also was estimated:

$$
\sigma M_{3}=\left(\frac{1}{M_{3}}-\frac{2}{3 M}\right)^{-1} \cdot \sqrt{\left(\frac{\sigma \Delta t}{\Delta t}\right)^{2}+\frac{4}{9}\left[\left(\frac{\sigma M_{1}}{M_{1}}\right)^{2}+\left(\frac{\sigma M_{2}}{M_{2}}\right)^{2}+\left(\frac{\sigma T}{T}\right)^{2}\right]}
$$

The next stage is the consideration of the mass transfer rate:

$$
\dot{M}=\frac{1}{3} \frac{\dot{P}}{P} \frac{M_{1} M_{2}}{M_{1}-M_{2}} .
$$

Error of the mass transfer rate:

$$
\sigma \dot{M}=\dot{M} \sqrt{\left(\frac{\sigma P}{P}\right)^{2}+\left(\frac{\sigma \dot{P}}{\dot{P}}\right)^{2}+\left(\frac{M_{2}}{M_{1}} \frac{\sigma M_{1}}{M_{1}-M_{2}}\right)^{2}+\left(\frac{M_{1}}{M_{2}} \frac{\sigma M_{2}}{M_{1}-M_{2}}\right)^{2}} .
$$

\section{Here:}

- $M_{1}, M_{2}, M_{3}$ are the masses of the components;

- $M$ is the sum of the components masses;

- $P$ is the period of variability;

- $\dot{P}$ is the rate of the period change (days per day);

- $\dot{M}$ is the rate of the mass transfer (solar masses per year);

- $c$ is the speed of light in vacuum;

- $G$ is the gravitational constant;

- $T, \Delta t$ are the period and amplitude of the $\mathrm{O}-\mathrm{C}$ oscillations;

- $\sigma P, \sigma \dot{P}, \sigma M_{1}, \sigma M_{2}, \sigma \Delta t, \sigma T$ are the errors of the period, rate of the period changes, masses of the binary system's components, amplitude and period of the $\mathrm{O}-\mathrm{C}$ oscillations.

The rate of the period change could be obtained by the approximation of the parabolic trend. The formula of parabola is well-known:

$$
\mathrm{O}-\mathrm{C}=\alpha t^{2}+\beta t+\gamma \text {. }
$$

Here parameter

$$
\alpha=\frac{\dot{P}}{2}
$$

is proportional to the rate of the period changes; $\beta$ is an error of the period in the moment $t=0 ; \gamma$ is the vertical shift (error of the initial epoch). Finally, we considered the elliptic shape of the orbit. There are 6 main orbital elements which completely describe the third component's motion:

- semi-major axis $(a)$;

- eccentricity $(e)$;

- three angles of inclination

- argument of the pericenter $(\Omega)$;

- inclination $(i)$;

- longitude of pericenter $(\omega)$;

- orbital period $(T)$;

- moment of the pericenter transit $\left(t_{0}\right)$. 


\section{DATA PROCESSING}

There were several stages in our research:

1. Collecting moments of minima from the database BRNO [41];

2. Collecting amateur observations from the AAVSO database [42];

3. Processing AAVSO observations using the MAVKA software [43];

(a) Splitting data onto separate minima;

(б) Cutting out extraeclipsing part of the minima (if necessary);

(в) Processing each individual minimum using symmetrical polynomial of statistically optimal order.

4. Combination of AAVSO and BRNO minima;

5. Plotting the $\mathrm{O}-\mathrm{C}$ curve and estimation of the initial values of orbital parameters by eye *;

6 . Correction of the orbital parameters by a modelling program;

7. Making plots of $\mathrm{O}-\mathrm{C}$ curve and deviations for visual control;

8. Calculation of the third component's mass;

9. Calculation of the mass transfer rate;

10. Estimation of the errors.

* Note: The Levenberg-Marquardt algorithm, which we used for the calculation of orbital parameters, needs an initial estimation. It could be done either using approximation with a simpler function or just by eye. The accuracy of the estimation is not really important, the coincidence in the order of value is enough. The accuracy of the final computation does not depend significantly on the initial estimation. Fluctuations for different initial conditions usually are smaller than errors of the final calculation.

All results of the calculations are provided in the Appendix section in tables and pictures.

\section{AAVSO OBSERVATIONS PROCESSING}

We took all avaliable data from the AAVSO database. There are observations in different filters made by various observers during several decades. For eclipsing binaries, the filter does not affect the moment of extremum. Firstly, we made the barycentric correction in the program MCV [44]. Then, we sorted the observations onto separate blocks. In each block there is only one filter and a single observer. That was done to split correctly the observations made at the same time. Finally, we split all data arrays onto separate minima and processed all of them with MAVKA.

We used only three of the nine MAVKA methods: WSP (wall-supported parabola), WSL (wall-supported line) and WSAP (wall-supported asymptotic parabola). These methods were created for the approximation of eclipsing binaries' minima. Software MAVKA automatically chooses the best of these three methods individually for each minimum by the least error of the moment of extremum. The algorithms, added to the subsequent versions of MAVKA, were described in detail in articles by Ivan L. Andronov and Kateryna D. Andrych [45-47].

\section{DISCUSSION AND CONCLUSIONS}

\begin{tabular}{|c|c|c|c|c|c|}
\hline Parameter & AR Lac & U CrB & S Equ & SU Boo & VV UMa \\
\hline$\alpha, 10^{-12}$ days $^{-1}$ & $-425 \pm 8$ & $77 \pm 8$ & $382 \pm 5$ & & \\
\hline$\beta, 10^{-7}$ & $391 \pm 7$ & $-299 \pm 2$ & $-336 \pm 4$ & $-46.9 \pm 0.3$ & $-58.6 \pm 0.2$ \\
\hline$\gamma, 10^{-3}$ days & $-957 \pm 15$ & $3 \pm 3$ & $751 \pm 9$ & $252 \pm 2$ & $261 \pm 1$ \\
\hline$a \sin i, 10^{6} \mathrm{~km}$ & $1420 \pm 30$ & $914 \pm 15$ & $548 \pm 12$ & $216 \pm 7$ & $419 \pm 9$ \\
\hline$e, 10^{-3}$ & $470 \pm 27$ & $389 \pm 30$ & $137 \pm 41$ & $264 \pm 47$ & $325 \pm 30$ \\
\hline$\omega$, rad & $-6.63 \pm 0.04$ & $4.79 \pm 0.06$ & $3.27 \pm 0.23$ & $0.35 \pm 0.23$ & $3.51 \pm 0.07$ \\
\hline$t_{0}, \mathrm{JD}-2400000$ & $-21390 \pm 610$ & $-19430 \pm 590$ & $3210 \pm 790$ & $4070 \pm 200$ & $6120 \pm 220$ \\
\hline$T$, days & $19000 \pm 140$ & $30930 \pm 280$ & $17380 \pm 180$ & $3088 \pm 9$ & $8750 \pm 30$ \\
\hline$\dot{M}, 10^{-9} \frac{M_{\odot}}{\text { year }}$ & $133 \pm 27$ & $1.55 \pm 0.16$ & $1.90 \pm 0.15$ & & \\
\hline$M_{3}, M_{\odot}$ & $1.746 \pm 0.067$ & $1.204 \pm 0.089$ & $0.750 \pm 0.057$ & $4.795 \pm 0.523$ & $0.820 \pm 0.069$ \\
\hline
\end{tabular}

Table 2 (Part 1). Orbital elements, masses of the third components and mass transfer rates for all 9 stars 


\begin{tabular}{|c|c|c|c|c|}
\hline Parameter & WW Gem & YY Eri & V0404 Lyr & HP Aur \\
\hline$\alpha, 10^{-12}$ days $^{-1}$ & & $212 \pm 2$ & & \\
\hline$\beta, 10^{-7}$ & $12.0 \pm 0.7$ & $-109.1 \pm 1.4$ & $11.17 \pm 0.05$ & $4.26 \pm 0.1$ \\
\hline$\gamma, 10^{-3}$ days & $-41 \pm 4$ & $85 \pm 3$ & $-75.0 \pm 0.3$ & $-21.2 \pm 0.5$ \\
\hline$a \sin i, 10^{6} \mathrm{~km}$ & $207 \pm 7$ & $271 \pm 2$ & $56.75 \pm 0.06$ & $56.9 \pm 0.6$ \\
\hline$e, 10^{-3}$ & $262 \pm 64$ & $416 \pm 12$ & $79 \pm 2$ & $153 \pm 20$ \\
\hline$\omega$, rad & $-1.08 \pm 0.26$ & $0.84 \pm 0.03$ & $2.78 \pm 0.03$ & $-7.38 \pm 0.13$ \\
\hline$t_{0}, \mathrm{JD}-2400000$ & $3010 \pm 300$ & $4610 \pm 190$ & $4980 \pm 20$ & $10560 \pm 80$ \\
\hline$T$, days & $2783 \pm 15$ & $16230 \pm 60$ & $640 \pm 0.2$ & $1590 \pm 3$ \\
\hline$\dot{M}, 10^{-9} \frac{M_{\odot}}{\text { year }}$ & & $259 \pm 31$ & & \\
\hline$M_{3}, M_{\odot}$ & $0.714 \pm 0.056$ & $0.530 \pm 0.040$ & $0.260 \pm 0.130$ & $0.457 \pm 0.033$ \\
\hline \multicolumn{5}{|r|}{} \\
\hline
\end{tabular}

Table 2 (Part 2)

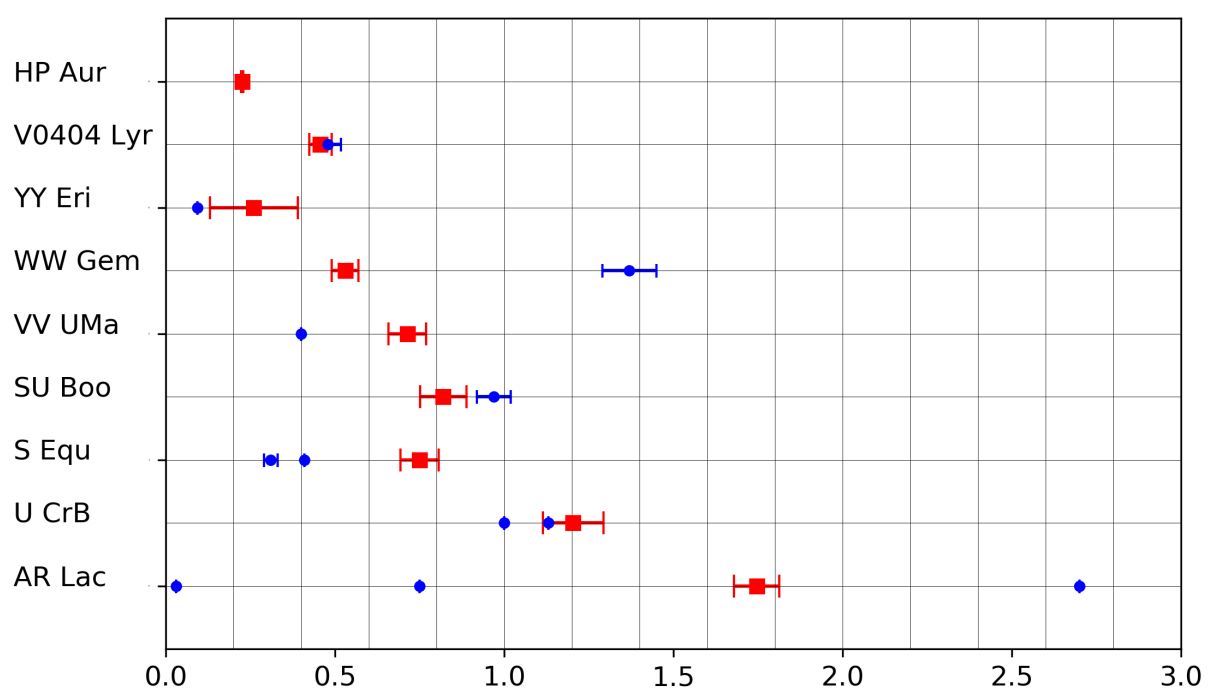

Fig. 10. Computed masses of the third components (squares) in comparison with previous results (dots)

For V0404 Lyr, U CrB, YY Eri and SU Boo, the values of the third components' masses are in good agreement with other authors' results. For HP Aur the third body's mass was computed for the first time. For VV UMa and $\mathrm{S}$ Equ, our values of the masses are significantly larger than previous results and for WW Gem our mass is much smaller than the published one. For AR Lac there exist both much smaller and much larger previous estimations. All these differences could be offributed to different data sets and models used by various authors.

Generally, our results should be more accurate than those in the previous publications, because we had a longer time scale of observations and obtained additional $\mathrm{O}-\mathrm{C}$ points from the AAVSO observations. In addition, we used a more precise model which consider noncircular orbits. Unfortunately, only several authors provi- ded errors of their calculations. Thus, a detailed comparison of the accuracy is not possible.

\section{ACKNOWLEDGMENTS}

We sincerely thank the AAVSO and BRNO associations of variable stars observers for their work that has made this research possible. In addition, we are grateful to Kateryna Andrych et al. who provided their software MAVKA for obtaining the moments of minima [45-47]. This research was done as part of the projects "Inter-Longitude Astronomy" (ILA) [51], Ukrainian Virtual Observatory (UkrVO) [52] and AstroInformatics [53], as well as previous research [54-55]. We express special gratitude to Leonid Shakun for the constructive discussion about the algorithm of the Python program. 
[1] N. N. Samus, E. V. Kazarovets, O. V. Durlevich, N. N. Kireeva, E. N. Pastukhova, Astron. Rep. 61, 80 (2017); https://doi.org/10.1134/S1063772917010 085.

[2] M. Zboril, J. M. Oliveira, S. Messina, G. Djurasevic, P. J. Amado, Contrib. Astron. Obs. Skalnate Pleso 35, 23 (2005).

[3] E. Raumer, Mon. Not. R. Astron. Soc. 427, 1702 (2012).

[4] J. P. De Greve, N. Mennekens, W. Van Rensbergen, L. Yungelson, Astron. Soc. Pacif. Conf. Ser. 404, 204 (2009).

[5] F. Mardirossian, M. Mezzetti, G. Giuricin, Astron. Astrophys. Suppl. Ser. 40, 57 (1980)

[6] C. Lázaro, M. J. Arévalo, A. Claret, E. Rodriguez, I. Olivares, Mon. Not. R. Astron. Soc. 325, 617 (2001); https : //doi.org/10.1046/j.1365-8711.2001.04437.x.

[7] Y.-G. Yang, Y. Yang, H.-F. Dai, X.-G. Yin, Astron. J. 148, 90 (2014); https ://doi.org/10.1088/0004-6256/ $148 / 5 / 90$.

[8] R. Nesci, C. Maceroni, L. Milano, G. Russo, Astron. Astrophys. 159, 142 (1986).

[9] Jae Woo Lee, Astron. J. 148, 37 (2014).

[10] D. S. Hall, J. M. Kreiner, Acta Astron. 30, 387 (1980).

[11] Chun-Hwey Kim, Astron. J. 102, 1784 (1991).

[12] L. Jetsu et al., Astron. Astrophys. 326, 698 (1997).

[13] J. D. Needham, J. P. Phillips, M. J. Selby, C. SanchezMargo, Astron. Astrophys. 83, 370 (1980).

[14] R. K. Srivastava, Acta Astron. 34, 291 (1984).

[15] Ye Lu, Fu-Yuan Xiang, Xiao-Min Shi, Publ. Astron. Soc. Jpn. 64, 84 (2012).

[16] A. I. Khaliullina, Astron. Rep. 62, 264 (2018); https: //doi.org/10.1134/S1063772918040030.

[17] M. T. Richards, A. S. Cocking, Proc. IAU Symp. 290, 301 (2012).

[18] E. Raymer, Mon. Not. R. Astron. Soc. 427, 17021712 (2012); https://doi.org/10.1111/j.1365-2966. 2012.22090.x.

[19] M. T. Richards, Proc. Int. Astron. Union Symp. 282, 167 (2012).

[20] M. I. Agafonov, O. I. Sharova, M. T. Richards, Astrophys. J. 690, 1730 (2009); https://doi.org/10.1 088/0004-637X/690/2/1730.

[21] S. K. Yerli et al., Mon. Not. R. Astron. Soc. 342, 1349 (2003); https://doi.org/10.1046/j.1365-8711. 2003.06644.x.

[22] G. J. Peters, R. S. Polidan, Bull. Am. Astron. Soc. 29, 835 (1997).

[23] G. E. Albright, M. T. Richards, Astrophys. Space Sci. 224, 415 (1995); https://doi.org/10.1007/BF006678 83.

[24] M. T. Richards, G. E. Albright, L. M. Bowles, Astrophys. J. 438, L103 (1995).

[25] J. Tomkin, D. L. Lambert, M. Lemke, Mon. Not. R. Astron. Soc. 265, 581 (1993); https://doi.org/10.108 6/187726.

[26] T. Borkovits, T. Hegedus, Odessa Astron. Publ. 7, 126 (1994); https://doi.org/10.1093/mnras/265.3.581.

[27] P. Mayer, M. Wolf, J. Tremko, P. G. Niarchos, Publ. House Czechoslovak Acad. Sci. 42, 4 (1991).

[28] J. R. W. Heintze, J. Am. Assoc. Var. Star Observers 19, 23 (1990).

[29] R. H. van Gent, Astron. Astrophys. Suppl. Ser. 77, 471
(1989).

[30] H. Forbes-Conde, T. Hertczeg, Astron. Astrophys. Suppl. Ser. 12, 1 (1973).

[31] G. A. Bakos, J. Tremko, Roy. Astron. Soc. Canada 75, 124 (1981).

[32] N. Mennekens, J.-P. De Greve, W. Van Rensbergen, L. R. Yungelson, Astron. Astrophys. 486, 919 (2008); https://doi.org/10.1051/0004-6361:200809530.

[33] F. Soydugan et al., Mon. Not. R. Astron. Soc. 379, 1533 (2007); https://doi.org/10.1111/j.1365-2966. 2007.12065.x.

[34] F. Soydugan, O. Demircan, E. Soydugan, C. Ibanoglu, Astron. J. 126, 393 (2003); https: //doi .org/10.1086/ 375643.

[35] S. B. Qian, L.Y. Zhu, Astrophys. J. Suppl. Ser. 142, 139 (2002); https://doi.org/10.1086/341253.

[36] Jae Woo Lee, Seung-Lee Kim, Kyeongsoo Hong, ChungUk Lee, Jae-Rim Koo, Astron. J. 148, 37 (2014).

[37] Brno Regional Network of Observers; http://var2 ast ro.cz/EN/.

[38] American Association of Variable Stars Observers; http $\mathrm{s}$ : //www . aavso.org.

[39] K .D. Andrych, I. L. Andronov, Open Eur. J. Var. Stars 197, 65 (2019).

[40] M. T. Richards, G. E. Albright, Astrophys. J. Suppl. Ser. 123, 537 (1999); https://doi.org/10.1086/313242.

[41] P. Zasche, M. Wolf, R. Uhlar, H. Kucakova, Astron. J. 147, 130 (2014); https://doi.org/10.1088/0004-625 $6 / 147 / 6 / 130$

[42] V. Simon, Astron. Astrophys. 311, 915 (1996).

[43] L. F. Snyder, in 32nd Annual Symposium on Telescope Science (Society for Astronomical Sciences, 2013), p. 179.

[44] I. L. Andronov, A. V. Baklanov, Astron. School Rep. 5, 264 (2004); https://doi.org/10.18372/2411-6602 .05 .1264 .

[45] K. D. Andrych, I. L. Andronov, L. L. Chinarova, Odessa Astron. Publ. 30, 57 (2017); https://doi.org/10.185 24/1810-4215.2017.30.118521.

[46] K. D. Andrych, I. L. Andronov, L. L. Chinarova, V. I. Marsakova, Odessa Astron. Publ. 28, 158 (2015).

[47] K. D. Andrych, I. L. Andronov, L. L. Chinarova, J. Phys. Stud. 24, 1902 (2020); https://doi.org/10.30970/jps .24 .1902 .

[48] J. B. Tatum, Physics topics. Celestial Mechanics; http: //astrowww.phys .uvic.ca/ tatum/celmechs/.

[49] Scipy library; https://www.scipy.org.

[50] Python; http://www.python.org.

[51] I. L. Andronov et al., Astron. Soc. Pacif. Conf. Ser. 511, 43 (2017).

[52] I. B.Vavilova et al., Proc. IAU Symp. No. 325, 361 (2017); https://doi.org/10.1017/S17439213170 01661.

[53] I. B. Vavilova et al., Kinem. Phys. Celest. Bodies 28, 85 (2012); https://doi.org/10.3103/S0884591312020 067.

[54] D. E. Tvardovskyi, V. I. Marsakova, I. L. Andronov, Odessa Astron. Publ. 30, 135 (2017); https://doi.or g/10.18524/1810-4215.2017.30.115463.

[55] D. E. Tvardovskyi, V. I. Marsakova, I. L. Andronov, L. S. Shakun, Odessa Astron. Publ. 31, 103 (2018); ht tps://doi .org/10.18524/1810-4215.2018.31.145280. 


\title{
ТРЕТІ КОМПОНЕНТИ З ЕЛІПТИЧНИМИ ОРБІТАМИ В ЗАТЕМНЮВАНИХ ПОДВІЙНИХ СИСТЕМАХ
}

\begin{abstract}
Д. Е. Твардовський ${ }^{1,2}$, В. І. Марсакова ${ }^{2}$, І. Л. Андронов ${ }^{1}$
${ }^{1}$ Одесъкий націоналъний морсъкий університет, кафедра математики фізики і астрономій

${ }^{2}$ Одесъкий націоналъний університет імені I. I. Мечникова, кафедра теоретичной фізики і астрономї̈

У нашому дослідженні ми вивчили 9 затемнюваних подвійних зір: AR Lac, U CrB, S Equ, SU Boo, VV UMa, WW Gem, YY Eri, V0404 Lyr, HP Aur. Зібрали великі масиви мінімумів із бази даних BRNO та спостережень із бази даних AAVSO. Відтак отримали моменти мінімумів для спостережень AAVSO (усього - 397 мінімумів) за допомогою методу апроксимації з симетричним поліномом, реалізованого в програмі MAVKA. Це програмне забезпечення надали Катерина Андрич та Іван Андронов. Після того ми поєднали отримані моменти мінімумів із даними, одержаними з BRNO, та побудували діаграми О-С. Для всіх зір ці діаграми являли собою подібні до синусоїдальних коливання з суперпозицією лінійного (для SU Boo, VV UMa, WW Gem, V0404 Lyr та HP Aur) або параболічного тренду (для AR Lac, U CrB, S Equ та YY Eri). Коливання можна описати як наявність третього компонента, що не бере участі в затемненнях, але викликає відомий light-time effect (LTE). Цей ефект можна легко виявити, використовуючи довгі серії даних. Однак коливання мають чітку асиметрію, яку ми інтерпретували як еліптичну форму орбіти третього компонента. Параболічний тренд ми пояснили як перетікання речовини між компонентами подвійної системи. Для всіх зір ми обчислили мінімально можливу масу третього компонента. Крім того, розробили власний код мовою програмування Рython та за його допомогою обчислили елементи орбіти третього компонента. Щобільше, для зір із параболічним трендом ми розраховували швидкість перетікання речовини. Урешті-решт, для всіх обчислених значень ми оцінили похибки.
\end{abstract}

Ключові слова: зоряна астрофізика, затемнювано-змінні зорі, перетікання речовини, треті компоненти, елементи орбіти, діаграма О-C. 